\title{
Light and optics conceptual evaluation findings from first year optometry students
}

Damber Thapa, Vasudevan Lakshminarayanan

Damber Thapa, Vasudevan Lakshminarayanan, "Light and optics conceptual evaluation findings from first year optometry students," Proc. SPIE 9289, 12th Education and Training in Optics and Photonics Conference, 928919 (17 July 2014); doi: 10.1117/12.2070519

SPIE Event: 12th Education and Training in Optics and Photonics Conference, 2013, Porto, Portugal 


\title{
Light \& Optics Conceptual Evaluation Findings from First Year Optometry Students \\ Damber Thapa ${ }^{1}$ and Vasudevan Lakshminarayanan ${ }^{1-3^{*}}$
}

\begin{abstract}
1School of Optometry and Vision Science, 2Department of Physics, 3Department of Electrical \& Computer Engineering, University of Waterloo,
\end{abstract}
Waterloo, Ontario, Canada

\begin{abstract}
The Light and Optics Conceptual Evaluation (LOCE) was developed to examine conceptual understanding of basic geometric and physical optics for the Active Learning in Optics and Photonics program administered by UNESCO. This 50 item test (46 multiple choice, 4 ray-tracing short answer) was administered to entering students in the Optometry professional degree (OD) program. We wanted to determine how much of the physics/optics concepts from undergraduate physics courses (a pre-requisite for entry to the OD program) were retained. In addition, the test was administered after the first year students had taken a required course in geometric and visual optics as part of their first semester courses. The LOCE was completed by two consecutive classes to the program in $2010(\mathrm{n}=89)$ and $2011(\mathrm{n}=84)$. The tests were administered the first week of the term and the test was given without any prior notice. In addition, the test was administered to the class of 2010 students after they had completed the course in geometric and visual optics. The means of the test were 22.1 ( $\mathrm{SD}=4.5$; range: 12-35) and 21.3( $\mathrm{SD}=5.1$; range: $11-35)$ for the two entering classes. There was no statistical significance between the two classes (t-test, $\mathrm{p}>0.05$ ). Similarly there was no difference between the scores in terms of gender. The post-course test (administered during the first week of the second term) showed a statistically significant improvement (mean score went from 22.1 to 31.1 , a $35 \%$ improvement).

It should be noted that both groups of students performed worse in questions related to physical optics as well as lens imaging, while scoring best in questions related to refraction and reflection. These data should be taken into consideration when designing optics curricula for optometry (and other allied health programs such as opticianry or ophthalmology).
\end{abstract}

Keywords: Active Learning, UNESCO, ALOP Project, Optometry, introductory optics

\section{INTRODUCTION}

\subsection{Optometry}

Optometry is a four year professional program leading to the degree of Doctor of Optometry (O.D.) in North America. In order to enroll in the professional program, most (if not all) students have already earned a Bachelor's degree in Science. A major pre-requisite is a full year (two semesters) of physics which includes both geometrical and physical optics. At our University, the University of Waterloo, for example, the pre-requisite includes Physics 111/121 or $121 / 122$ with associated laboratories. Once in the program, throughout the four years, students take courses that cover basic optics and visual optics, visual neurophysiology, and clinical techniques along with the health and diseases of the human visual system. OD students also study cell and molecular biology, pharmacology, genetics, epidemiology, clinical technology, ethics and practice management. At the end of the first two years of the 4 year long program, the student is expected to build a base of knowledge in the basic sciences of health, disease, optics and visual sciences. One can argue in fact that optics is the basic bread and butter of the profession. In fact, during the first year students take 3 courses on optics, one on geometric and visual optics (some schools in the United States have two courses, one on geometric optics and a second on physical optics), one on visual optics and a third on ophthalmic optics. For more details see reference 1. Therefore it is logical to ask how much of optics knowledge incoming students bring when they enter the program. This will allow the educator to tailor the courses so as to not be redundant or repetitive and build up on existing knowledge.

*phone:1-519-888-4567ext38167;email:vengu@uwaterloo.ca 


\subsection{Light and Optics Conceptual Evaluation}

In its efforts to promote creativity and innovations in the way introductory physics is taught in the university, UNESCO (United Nations Educational and Scientific Organization) has supported activities in different developing countries to address the need for teacher upgrading and introducing innovative learning approaches. In recent years, the focus has been active learning approach ${ }^{2-6}$, including developing teaching and learning materials. The focus of the UNESCO Active Learning in Optics and Photonics project begun in 2003 and is based on one of the experimental physics areas that is relevant and adaptable to research and educational conditions in many developing countries. Optics has been termed an enabling science is the basis for many advances in high technology. This project was developed for the benefit of university and senior high school physics teachers from developing countries and aims to train and better equip them to teach the optics part of the introductory physics course by using active learning with hands-on activities and by drawing examples from local research activities. At these workshops, an introductory test, called the Light and Optics Conceptual Evaluation (LOCE) test is administered to the participants both before and after the workshop to gauge the effectiveness of the active learning methodology.

The Light and Optics Conceptual Evaluation (LOCE) was developed to examine conceptual understanding of basic geometric and physical optics for the Active Learning in Optics and Photonics program administered by UNESCO ${ }^{7}$. This 50 item test (46 multiple choice, 4 ray-tracing, short answers) was administered to entering students in the Optometry professional degree (OD) program. We wanted to determine how much of the physics/optics concepts from undergraduate physics courses (a pre-requisite for entry to the OD program) were retained. In addition, the test was administered after the first year students had taken a required course in geometric and visual optics as part of their first semester courses. In this paper we present the results of the LOCE exam administered to two consecutive classes to the program in $2010(\mathrm{n}=89)$ and $2011(\mathrm{n}=84)$. The tests were administered the first week of the term and the test was given without any prior notice. In addition, the test was administered to the class of 2010 students after they had completed the course in geometric and physical optics.

\section{METHODS}

First year students who were admitted to the years 2010 and 2011 (graduating class of 2014 and 2015) were included in this study. The 2010 year group had both pre-term and post-term scores while the 2011 year group just had pre-term scores. The demographic description of the data is shown in Table 1.

The t-test was used to see the difference between the two groups. Paired t-test was used to examine the improvement in the fundamental concepts of optics. Bland-Altman analysis was performed to examine the agreement between the preterm and post-term scores. GraphPad Prism 6 was used to analyze the data. The changes in test scores were calculated using Eq. 1.

Percent change $=($ post-term score-pre-term score $) /($ pre-term score $) \times 100 \%$

Table 1: Group Statistics of all the participants

\begin{tabular}{cccc}
\hline \hline Groups & Male & Female & Total \\
\hline Pre-term 2010 & 29 & 60 & 89 \\
Post-term 2010 & 25 & 54 & 79 \\
Pre-term 2011 & 18 & 66 & 84 \\
\hline \hline
\end{tabular}




\section{RESULTS}

Table 2: Group Statistics of pre-term score

\begin{tabular}{ccc}
\hline \hline Groups & Pre-term 2010 & Pre-term 2011 \\
\hline Number of student & 89 & 84 \\
Minimum & 12.00 & 11.00 \\
Maximum & 35.00 & 35.00 \\
Median & 22.00 & 21.00 \\
Mean & 22.09 & 21.25 \\
Std. Deviation & 4.547 & 5.082 \\
Std. Error of Mean & 0.4820 & 0.5545 \\
Lower 95\% CI of mean & 21.13 & 20.15 \\
Upper 95\% CI of mean & 23.05 & 22.35 \\
\hline \hline
\end{tabular}

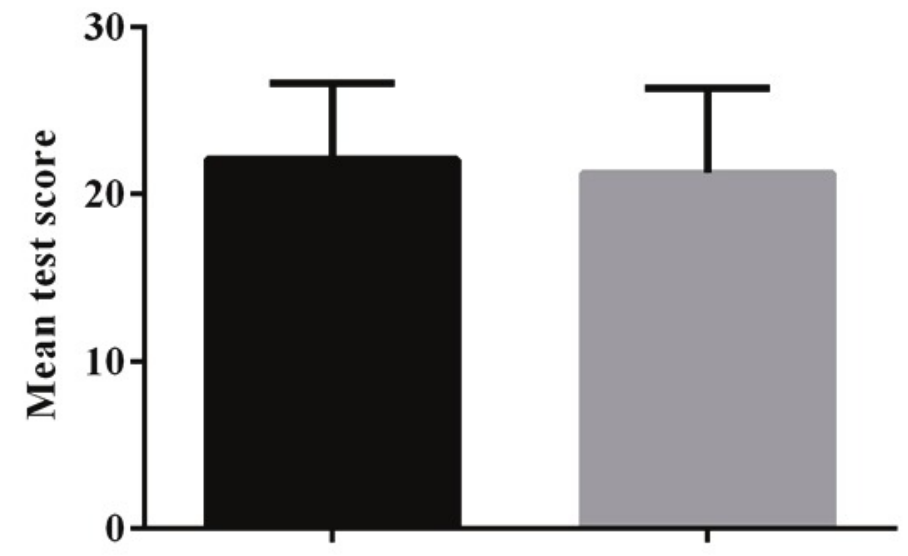

\section{Pre-term score $2010 \quad$ Post-term score 2011}

Figure 1: Mean Values of pre-term score of 2010 and 2011 year groups

\subsection{Pre-term 2010 score vs. Pre-term 2011 score}

The group statistics is shown in Table 2. Fig. 1 shows the mean values of the pre-term scores for the two years. To examine the differences between the two years, a student's t-test was conducted, assuming both groups have the same standard deviation. No significant differences were found between the two mean scores $(\mathrm{t}(171)=1.147 ; \mathrm{p}=0.253)$. The F- test was conducted to test the variances and no significant difference was found $(\mathrm{F}(83,88)=1.249 ; \mathrm{p}=0.304)$. This result indicates that the two populations were not significantly different.

\subsection{Gender differences of pre-term scores of 2010 and 2011 students}

The group statistics and mean values of the pre-term scores of the two populations are shown in Tables 3 and 4 and in Fig. 2 and Fig. 3 below. 
Table 3: Group Statistics of pre-term score for male and female in year 2010

\begin{tabular}{ccc}
\hline \hline Groups & Male 2010 & Female 2010 \\
\hline Number of students & 29 & 60 \\
Minimum & 12.00 & 13.00 \\
Maximum & 35.00 & 31.00 \\
Median & 23.00 & 21.00 \\
Mean & 23.62 & 21.35 \\
Std. Deviation & 5.185 & 4.046 \\
Std. Error of Mean & 0.9629 & 0.5223 \\
Lower 95\% CI of mean & 21.65 & 20.30 \\
Upper 95\% CI of mean & 25.59 & 22.40 \\
\hline \hline
\end{tabular}

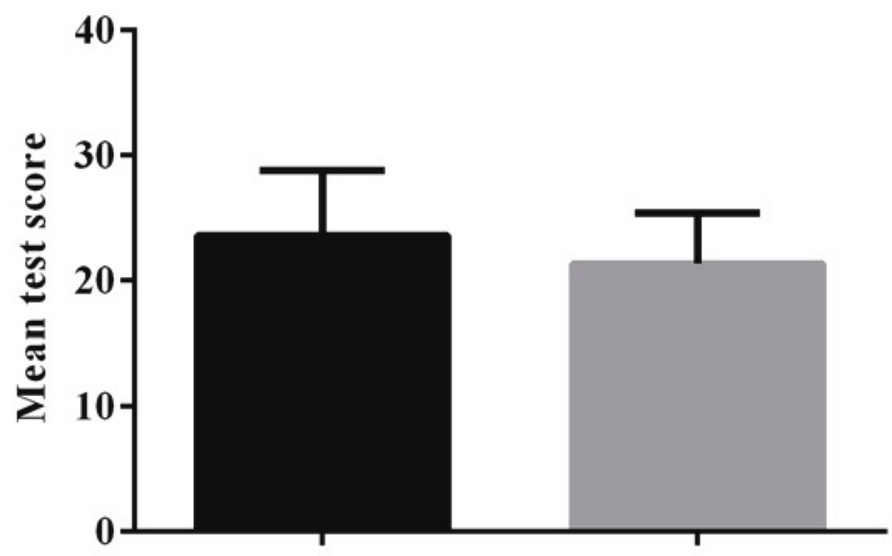

Male 2010

Female 2010

Figure 2: Mean values of male and female pre-term score for 2010 year

Table 4: Group Statistics of pre-term score for male and female in year 2011

\begin{tabular}{ccc}
\hline \hline Groups & Male2011 & Female2011 \\
\hline Number of students & 18 & 66 \\
Minimum & 12.00 & 11.00 \\
Maximum & 35.00 & 35.00 \\
Median & 23.00 & 20.50 \\
Mean & 23.22 & 20.71 \\
Std. Deviation & 5.631 & 4.829 \\
Std. Error of Mean & 1.327 & 0.5944 \\
Lower 95\% CI of mean & 20.42 & 19.53 \\
Upper 95\% CI of mean & 26.02 & 21.90 \\
\hline \hline
\end{tabular}




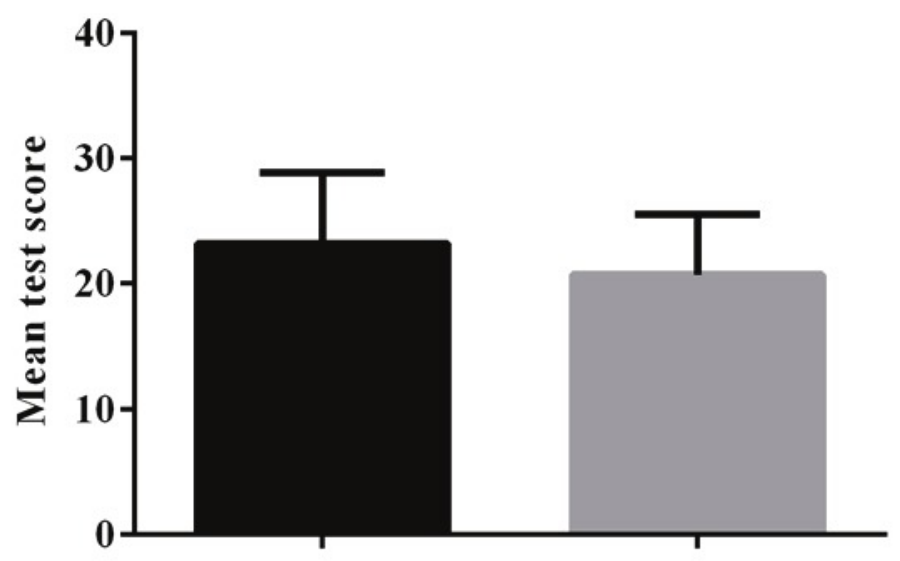

Male 2011

Female 2011

Figure 3: Mean values of male and female pre-term score for 2011

To examine the difference in mean values between males and females for both classes, a t-test was conducted. Significant difference was found between the genders for the 2010 group $(\mathrm{t}(87)=2.259 ; \mathrm{p}=0.0264)$; however, no significant difference was found between the two mean scores for the 2011 group $(\mathrm{t}(82)=1.886 ; \mathrm{p}=0.0629)$. No significant differences were found between the variances for both classes using the F-test.

Given the fact that both the 2010 and 2011 populations did not significantly differ and the variances were the same, we combined both populations and carried out a gender difference study. The group statistics is shown in Table 5 and the mean values are shown in Fig. 5. Significant differences were found male vs. female mean scores using the t-test $(\mathrm{t}(171)=3.048 ; \mathrm{p}=0.0027)$ and the variances were not significantly different $(\mathrm{F}(46,125)=1.41 ; \mathrm{p}=0.14)$.

Table 5: Group Statistics combining both years

\begin{tabular}{ccc}
\hline \hline Groups & Total male & Total female \\
\hline Number of students & 47 & 126 \\
Minimum & 12.00 & 31.00 \\
Maximum & 35.00 & 21.00 \\
Median & 23.00 & 21.02 \\
Mean & 23.47 & 4.467 \\
Std. Deviation & 5.303 & 0.3979 \\
Std. Error of Mean & 0.7736 & 20.23 \\
Lower 95\% CI of mean & 21.91 & 21.80 \\
Upper 95\% CI of mean & 25.03 & 23 \\
\hline \hline
\end{tabular}




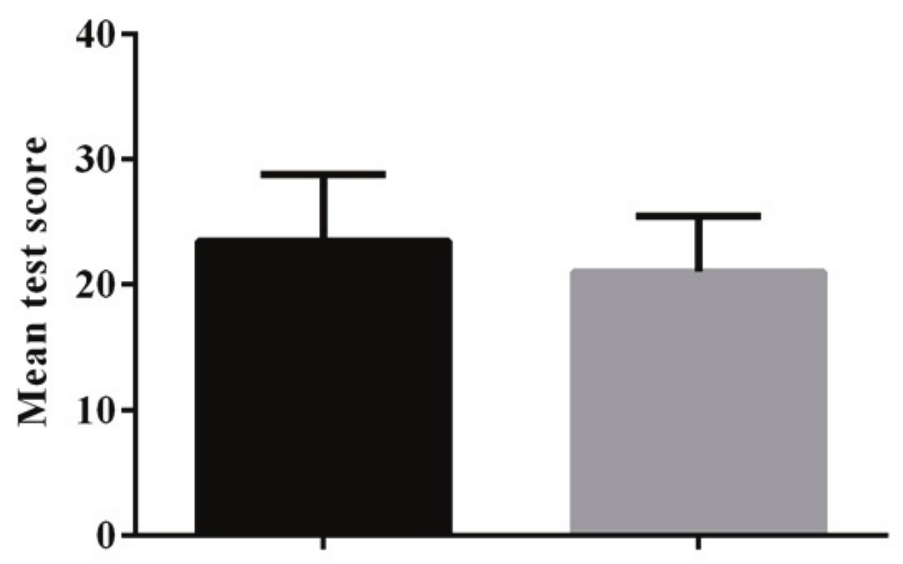

\section{Total Pre-term male Total Pre-term Female}

Figure 4: Combined male vs. female mean pre-term score for both years

\subsection{Pre-term vs. Post-term results}

As noted earlier, the same test was given approximately three weeks after the end of the term to the 2010 class. We were unable to administer the test to the class of 2011. The group statistics and mean values are shown in Table 6 and Fig. 5. The percentage changes were calculated using Eq. 1 and the change was calculated to be approximately $36 \%$ increase in conceptual understanding overall. In terms of gender, males showed a $37 \%$ change in mean scores, while females showed a $35 \%$ changes between the two mean scores. In both genders a significant change was found in pre- and postterm scores.

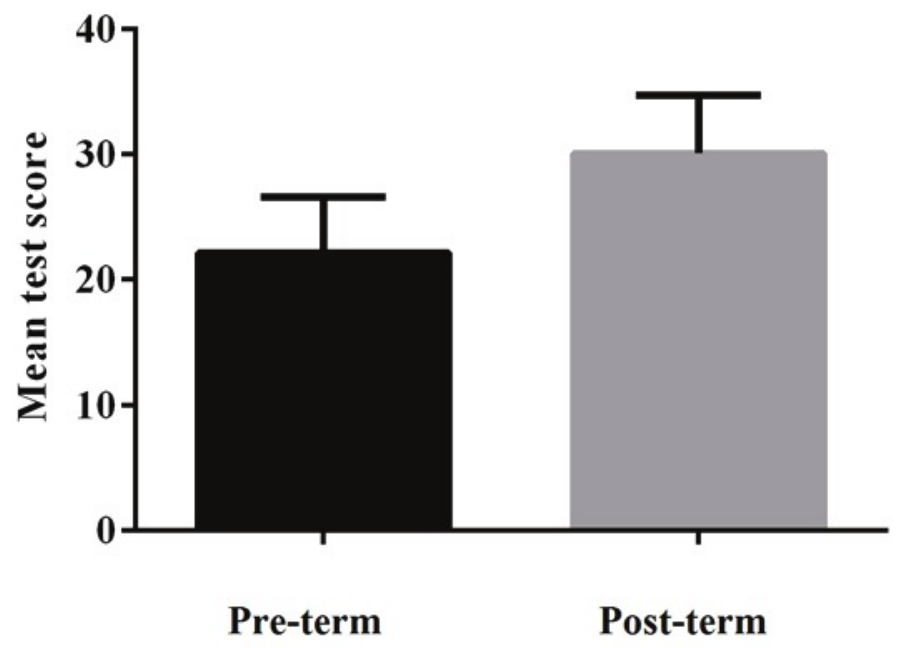

Figure 5: Mean pre- and post- terms results of the 2010 class 
Table 6: Group statistics of the pre- and post- term results for the 2010 class

\begin{tabular}{ccc}
\hline \hline Groups & Pre-term & Post-term \\
\hline Number of students & 79 & 79 \\
Minimum & 12.00 & 19.00 \\
Maximum & 35.00 & 39.00 \\
Median & 22.00 & 30.00 \\
Mean & 22.16 & 30.09 \\
Std. Deviation & 4.459 & 4.677 \\
Std. Error of Mean & 0.5017 & 0.5262 \\
Lower 95\% CI of mean & 21.17 & 29.04 \\
Upper 95\% CI of mean & 23.16 & 31.14 \\
\hline \hline
\end{tabular}

A Bland Altman analysis was done (Figure 6). The results show that the bias is 7.924 and the bias is 4.997. The $95 \%$ limit of agreement extends from -1.870 to 17.72 .

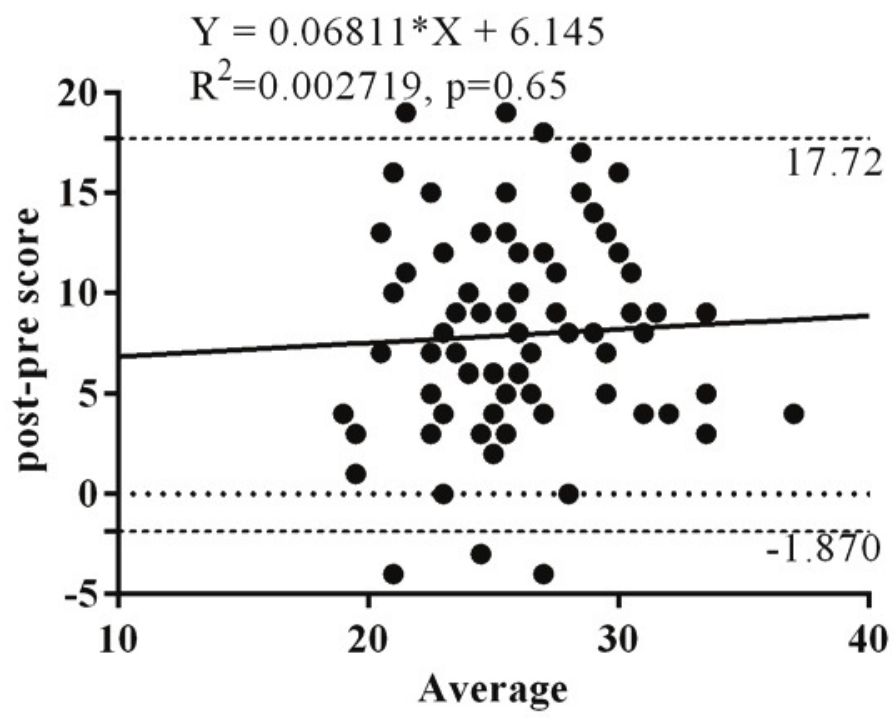

Figure 6: Bland-Altman test between pre- and post-term test scores

\section{DISCUSSION AND CONCLUSIONS}

The LOCE test was administered to two entering classes of optometry students at the University of Waterloo, School of Optometry and Vision Science. The LOCE test instrument which as developed by the UNESCO ALOP Team consists of 50 multiple choice questions covering a variety of areas in introductory optics (4 question on reflection and mirrors, 5 on Snell's law, 7 on lenses, 15 on imaging, 2 on visual optics, 8 on polarization and scattering, 8 on wave optics, interference and diffraction) and a ray tracing exercise.

Detailed analysis of the answers revealed that students did best (fewest errors) on questions related to refraction/reflection and Snell's law and made the most mistakes in questions related to physical optics and imaging by lenses. It should be noted however, that all introductory texts on physics currently in use for the pre-requisite courses for entry into optometry programs all include chapters/sections on physical optics. It is possible to argue that students 
would have forgotten the material in the gap year(s) between taking introductory physics and entry into optometry school. However, it should be noted that all entering students have to take an entrance test, called the Optometry Admissions Test (OAT) which includes a section on physics. The fact that students do not have a satisfactory conceptual understanding of diffraction, interference, polarization, lens imaging, etc. has consequences for the optometry curriculum. As noted elsewhere ${ }^{1}$ the students encounter these concepts in other areas of their education in vision science. This implies that these areas should be emphasized (with more time given to lens imaging, and physical optics) in the curriculum and more time spent on these topics, with lesser time devoted to refraction and Snell's law. Given the increasing sophistication of optometric technology and procedures (laser surgery, wavefront aberration measurement and correction, etc.), it is imperative that optometry students get a good conceptual understanding of these topics, so that they can be ready for assimilating future knowledge. This information should be taken into consideration when designing optics syllabi for optometric curricula. This is also important for other optical health professions such as Ophthalmology and Optician courses. Of course, it works the other way around also - it has been argued that the human eye is the best model to teach optics ${ }^{8}$

We were able to complete only one follow up, post-term, administration of the test. There was a significant improvement in test scores. This course has been a traditional lecture (3 hours/week lecture and 1 hour tutorial session with a two hour laboratory). However, it has been shown that methods like interactive lecture demonstrations and active learning methodologies lead to even better scores (and the ability to retain the concepts) compared to traditional lecture methodology 9 . This needs to be further evaluated. Here we are unable to assess the long-term effects of the course in terms of retaining concepts learnt. We hope to do further testing at not only our institution but also at other colleges and schools of optometry.

\section{ACKNOWLEDGEMENTS}

We would like to thank Professor Natalie Hutchings, who gave us permission to administer the test in her class OPT 106 during the fall terms of 2010 and 2011.

V.L. is also affiliated with the Michigan Center for Theoretical Physics, University of Michigan, Ann Arbor, MI 48109,USA.

\section{REFERENCES}

[1] Lakshminarayanan, V., :Teaching Optics in a Multidisciplinary curriculum: experience from Optometry", Education in Optics and Photonics, Ottawa, http://spie.org/etop/2007/etop07nanoIV.pdf (2007)

[2] Alarcon, M., Ben Lakhdar, Z., Culaba, I., Lahmar, S., Lakshminarayanan, V., Mazzolini, A., Maquiling, J., Niemela, J. " Active learning in optics and photonics: a model for teacher training and professional development:, Proc SPIE, 77833, DOI: 10.1117/12.860708; http://spie.org/x648.html?product_id=860708 (2010)

[3]. Alarcon, M., Arthurs, E., Ben lakhdar, Z., Culaba, I., Lakshminarayanan, V., Maquiling, J., Mazzolini, A., , Niemela, J., and Sokoloff, D., "Active learning in optics and photonics: achievements and outcomes to date", ETOP meeting, Ottawa, 2007.

[4]. ibid, "Active learning in optics and photonics: experiences in Africa", ETOP 2005

http://spie.org/etop/etop2005 040.pdf (2005)

[5] D. Sokoloff, P. Laws, and R. Thornton, "RealTime Physics: active learning labs transforming the introductory

laboratory", European Journal of Physics 28 S83-S94 (2007).

[6] Masters, M.F., and Grove, T.T., "Active Learning in intermediate Optics thorugh class tutorials and concept building laboratories", ETOP 2009, http://spie.org/etop/2009/etop2009 3b.8.2.pdf (2009)

[7]. Sokoloff, D. (Ed.), Active Learning in Optics and Photonics, Manual, UNESCO, Paris, 2006

[8] Lakshminarayanan, V. "The human eye as a model system for teaching optics", ETOP 2009, http://spie.org/etop/2009/etop20093b.8.75.pdf (2009)

[9] Lakshminarayanan V, "Interactive lecture demonstrations, active learning and the ALOP project", Eco-Photonics, Proc. SPIE 8065, doi: 10.1117/12.889508 (2011), 